\title{
INTERAÇĀO VERBAL ENTRE A EQUIPE DE ENFERMAGEM E O PACIENTE AIDETTCO *
}

\author{
Elucir Gir ** \\ Tokico Murakawa Moriya***
}

GIR, E. \& MORIYA, T.M. Interação verbal entre a equipe de enfermagem e o paciente aidético. Rev. Esc. Enf. USP, São Paulo, 24(2):301-313, ago. 1990.

Nestie estudo foram analisados 3.336 comportamentos verbais ocorridos entre 17 elementos da equipe de enfermagem e 3 pacientes aidéticos. Determinaram-se o padrão $e$ áreas prioritárias de comportamentos verbais, segundo o sistema SAVI, bem como a quantidade de informação transmitida.

Os resultados mostraram que os comportamentos verbais variaram de relativa ambigüidade quanto à clareza das mensagens até mensagens limpas e náa-contraditórias. A tendência das interações ocorridas foi de se distanciarem da estereotipia.

UNITERMS: AIDS. Relações enfermeira-paciente.

\section{INTRODUÇĀO}

Se as doenças transmissiveis por si só, são carregadas de estigma e preconceitos, quando se fala em AIDS, estes aspectos são acentuados, pois, além de transmissiveis, trata-se de uma doença fatal, associada principalmente ao uso de drogas e práticas homossexuais; comportamentos estes bastante discriminados pela sociedade.

CHRISTI \& WIENER (1985) e ROSNER; SHAPIRO; BERNABO; HOWARD (1985) relataram que este estigma associado ao medo das pessoas contraírem a referida doença, levam os pacientes a serem rejeitados pela sociedade, abandonados pela família e amigos e sentirem-se inferiorizados.

NICHOLS (1983) e OLIVEIRA, VIETTA, MORIYA, GIR (1987), relatam que as reações observadas nos pacientes são as mais diversas, tais como sentimento de culpa, negação, medo, tristeza, revolta, vergonha, ira, sentimentos de inferioridade.

Segundo GILLON (1987) e KELLY, LAWRENCE, SMITH, HOOD, COOK (1987), os estigmas são extensivos também a muitos profissionais de saúde, que até se recusam assistir pacientes contaminados ou com AIDS.

Como refere LACAZ (1985), a AIDS trouxe à tona o medo e o pânico, levando à alterações significativas das interações interpessoais

\footnotetext{
** Assistente do Departamento de Enfermagem Geral e Especializada da Escola de Enfermagem de Ribeiržo Preto - USP.

*** Professor Assistente Doutor do Departamento de Enfermagem Geral e Especializada da Escola de Fnfermagem de Ribeiräo Preto-USP (Orientadora da Pesquisa).
} 
no contexto social em que vivemos. Vem, sobretudo, modificando comportamentos, suscitando óảios, despertando preconceitos e até mesmo lendas. No âmbito hospitalar tal fato não poderia repercutir de modo diferente, pois aliado ao preconceito surgiu o medo de cuidar destes pacientes (MACIEL, 1987). Urge-se portanto, a humanização nos hospitais.

Para MEZOMO (1979), a humanização do hospital não se faz sem pessoal suficiente e qualificado. Segundo este mesmo autor, humanizar o hospital consiste em recriar laços entre homens doentes e os homens que se propõem a cuidá-los.

Frente ao exposto decidiu-se explorar como a equipe de enfermagem vem interagindo junto a pacientes aidéticos, especificamente no que se refere à comunicação verbal. Vários autores (FAULKINER, 1979; HEWITT \& PESZNECKER, 1964; (STOCKWELL, 1972 apud CLARK, 1981) apontam falhas na comunicação entre pacientes gerais e equipe de enfermagem. No nosso meio estas falhas também são evidenciadas; a necessidade de mudança na interação entre o enfermeiro e o paciente é apontada, conforme constata-se nas pesquisas de CARVALHO (1979); CARVALHO (1985) e MENDES (1986).

Os trabalhos consultados abordam pacientes portadores de doenças agudas ou crônicas de forma geral, sendo que a literatura sobre comunicação em Enfermagem no campo das Doenças Transmissiveis é restrito.

Os modelos teóricos utilizados no estudo da comunicação são variados, porém nenhum foi encontrado que utilizasse o modelo por nós proposto, ou scja o sistema SAVI (Sequential Analysis of Verbal Interaction) e a Teoria da Informação.

\section{Objetivas:}

a) Determinar o padrão e áreas de comportamentos verbais prioritariamente ocorridos, segundo sistema SAVI, entre Aidéticos internados num hospital geral brasileiro e a Equipe de Enfermagem que os assiste;

b) Determinar a variabilidade nas interaçōes verbais.

\section{METODOLOGIA}

A pesquisa foi realizada em uma unidade de internação de um hospital geral de grancic porte da cidade de Ribeirão Preto - SP, Brasil.

Correspondeu à amostra 90 horas de observação junto a três enfermeiras, dez auxiliares de enfermagem, quatro atendentes de enfermagem - enquanto desempenhavam suas atividades profissionais rotineiras no periodo estabelecido e que entraram nas enfermarias em observação, quer por designação de escala de serviço, quer por outro motivo qualquer - e três pacientes.

Para a inclusão dos pacientes consideraram os critérios: estar com AIDS, ter idade entre 20 e 35 anos, ser do sexo masculino, estar inter- 
nado numa enfermaria individual; ter previsão de hospitalização minima de cinco dias a partir do primeiro dia de observação; estar consciente; estar contactuando verbalmente; estar auto e alopsiquicamente orientado e aceitar ser observado.

Cada paciente foi observado durante 30 horas, de segunda a sexta feira, no periodo das 7 às 13 horas. Quatro observadores, previamente orientados, treinados e calibrados se rodiziavam entre si de tal forma que sempre um deles se mantinha dentro da enfermaria, para proceder à observação e ao registro dos comportamentos verbais que ocorressem.

Valeu-se das técnicas de observação do tipo relato cursivo e de registro com lápis e papel.

Os dados obtidos constituiram os protocolos de interação verbal, os quais foram analisados por três juizes, previamente treinados e calibrados, conforme descrito detalhadamente por GIR (1988). Os periodos de observação foram divididos em unidades de interação e classificados, à luz dos pressupostos teóricos do System of Analysis of Verbal Interaction (SAVI), de autoria de SIMON \& AGAZARIAN (1967).

Após o julgamento dos comportamentos verbais contidos nos protocolos, estes foram lançados manualmente na matriz SAVI, respeitandose o emissor e o receptor de cada mensagem e a sessão de observação.

A matriz SAVI é uma grade formada por 28 linhas horizontais e 28 linhas verticais, que formam 784 células e que representam nove áreas de comportamentos verbais $(\mathrm{A}, \mathrm{B}, \mathrm{C}, \mathrm{D}, \mathrm{E}, \mathrm{F}, \mathrm{G}, \mathrm{H}, \mathrm{F}$,$) . Cada área é denomi-$ nada, considerando-se que o comportamento verbal pode ser classificado como um comportamento que aproxima ou afasta a informação pessoal e/ou temática, o que está relacionado à clareza ou não das mensagens enviadas. Em cada área estão inseridas categorias, sendo que cada comportamento verbal lançado em cada célula, corresponde ao ponto de intersecção entre duas categorias (Figura 1).

As matrizes, tabelas e quadros foram analisados com base nas freqüências simples e percentual e usou-se, também, um programa para o processamento eletrônico dos dados para o cálculo de $\mathrm{R}$ ou seja, da quantidade de informação transmitida.

Para este cálculo, empregou-se a fórmula preconizada por FAVERGE (1954) e STEPHANECK (1971), ou seja:

$$
\begin{aligned}
& R_{\text {relativo }}=\frac{R_{\text {atual }}}{\text { Tog do menor } i \text { ou } J} \text {, onde } \\
& R_{\text {atual }}=\sum n_{i j} \log _{2} n_{i j}-\sum n_{i} \log _{2} n_{i}-\sum n_{j} \log _{2} n_{j}+N \log _{2} N
\end{aligned}
$$


sendo:

$\mathrm{n}_{1 \jmath}=$ número de respostas contidas na intersecção da linha $i$ e da coluna $j$.

$\mathrm{n}_{\mathrm{i}}=$ número de respostas total na linha $i$

$\mathrm{n}_{\mathrm{j}}=$ número de respostas total na coluna $j$

$\mathrm{N}=$ número de respostas total na tabela.

$\Sigma=$ menor $i$ ou $j=28$

EDWARDS (1971) e STEPHANECK (1971), elucidam que $R$, define estatística de correlação entre duas variáveis ( $\mathrm{x}$ e $\mathrm{y}$ ), que correspondem, respectivamente, à emissão e recepção das informações. Tem sempre valor positivo ou nulo e deve ser calculado, usando logarítmos na base dois.

Localizando $\mathrm{R}$ num diagrama de Venn, representativo das várias quantidades de informações implicadas num sistema de transmissão, ter-se-ia, conforme citação destes autores:

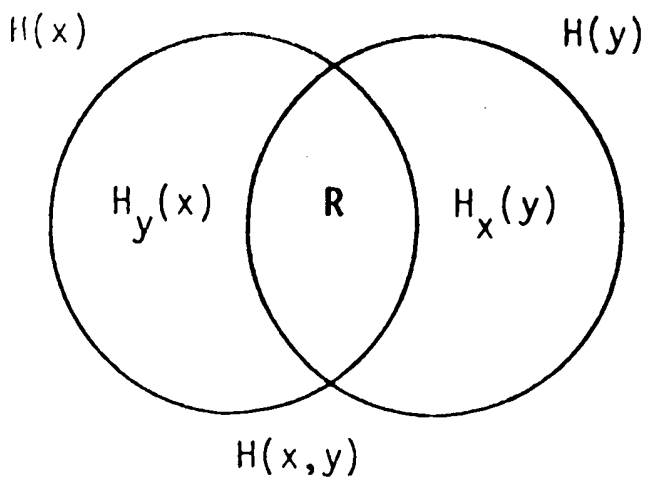

oncic:

$\mathrm{R}=$ quantidade de informação transmitida, isto é, informação emitida (presente na entrada) e recebida (presente na saida);

$\mathrm{H}(\mathrm{x})$ = entropia da fonte ou quantidade de informação emitida pela fonte;

$\mathrm{H}(\mathrm{y})$ = entropia da recepção ou quantidade de informação, contida na resposta do sujeito;

$\mathrm{Hy}(\mathrm{x})=$ é a informação emitida, mas que se perdeu. $\mathbf{E}$ chamado de "equivoco";

$\mathrm{Hx}(\mathrm{y})=$ é a informação recebida, ou seja, informação presente na saída, mas não na entrada. E o que se chama de ambigüidade ou ruído;

$\mathrm{H}(\mathrm{x}, \mathrm{y})=$ entropia total ou quantidade total de informação, presente no sistema. 
FIGURA I

Matriz SAVI: 9 áreas, 28 categorias, 784 :élulas

AF ASTAMENTO

PESSOAL
POTENCIN

T E M A
APROXIMACAO

PESSOAL E/OU TEMA

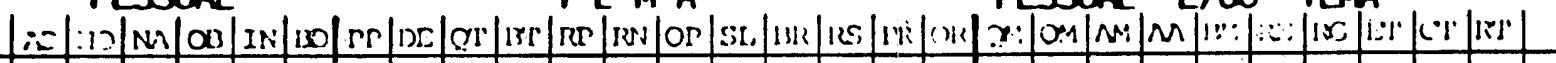

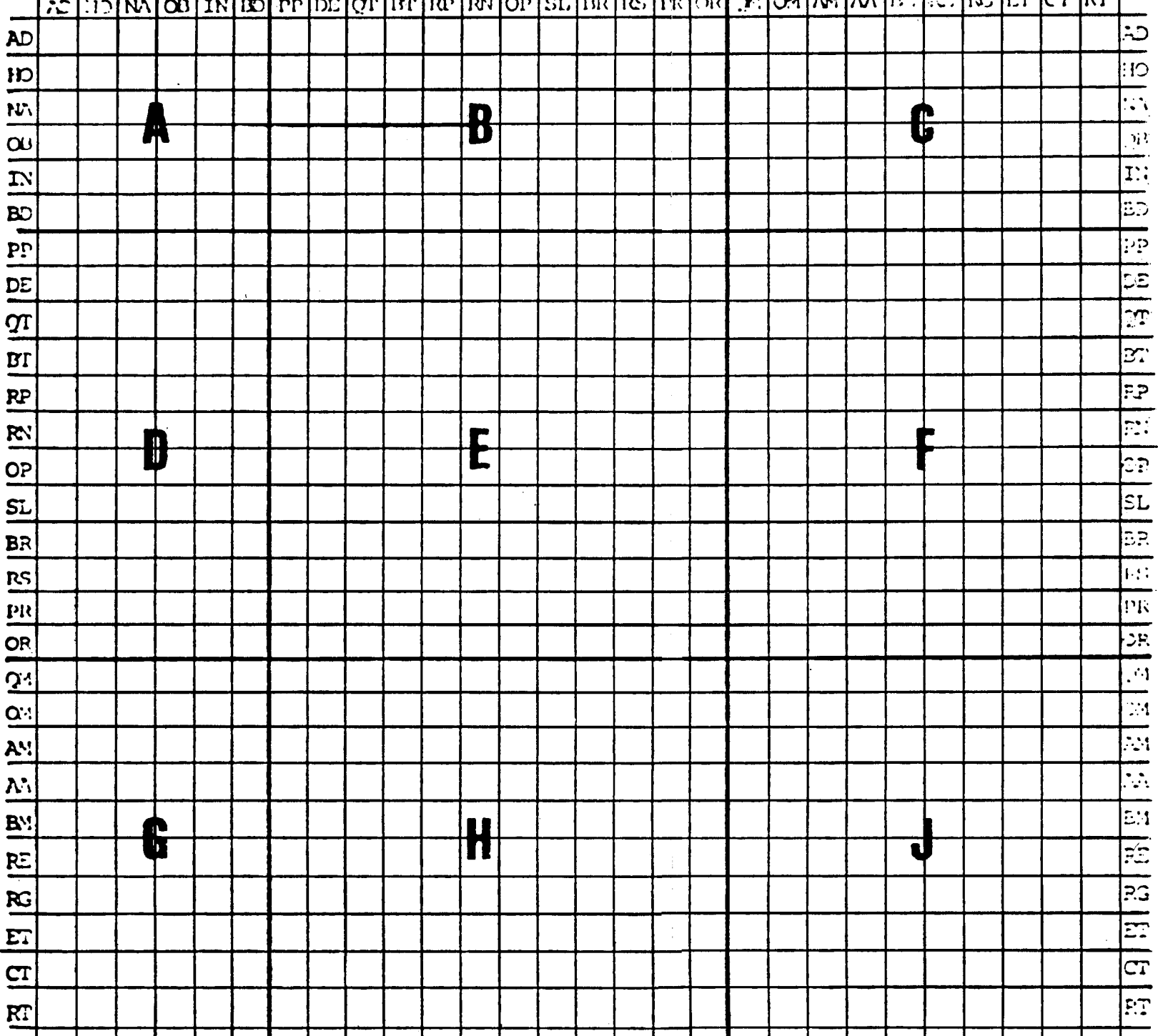

POTENCIAL

APROXIMACATO

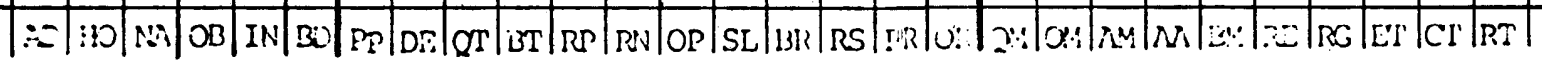

(ADAPTADO DE SIMON \& AGAZARIAN, 1967)

D - Narrativa; $O B=$ Obrigatoriedade; $I N=$ Intelectualidade; $B D=$ Brincadeira Defensiva: PP = Participacão Pessoal; DE = Descrição; QT - Questão sobre o Tema: Bi = Brincadeira sobre o Tema; RP - Resposta Positiva: $\mathrm{RN}=$ Resposta Negativa; OP = Opiniáo; SL - Silencio; BR $=$ Barulho; RS $=$ Riso; PR $=$ Proposta; OR $=-{ }^{2}$ Ordem; QM $=$ Questão de Manutenção; OM $=$ Oferece Manutença; AM $=$ Apoia Manutenção; AA de Manutencão; $\mathbf{R E}=$ Resposta Especifica; $\mathbf{R G}=$ Resposta Geral; $\mathbf{E T}=$ Esclarecimento sobre 0 $\mathrm{RT}=$ Reflexão sobre o Tema.

AREAs: $\mathbf{A}=$ Afastamento de manutenção pessoal; $\mathbf{B}=$ Afastamento do tema; $\mathbf{C}=$ Afastamento do tema e/ou da manutenção pessoal;

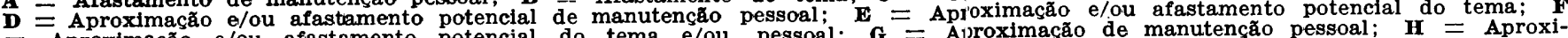
Aproximação e/ou afastamento potencial do tema e/ou 


\section{RESULTADOS E DISCUSSÃO}

ticas:

Os sujeitos incluíảos neste estudo portavam as seguintes caracterís-

PACIENTE $\mathrm{P}_{1}$ : 21 anos, sexo masculino, cor branca, solteiro, nivel de escolaridade fundamental, profissão: ajudante de cozizinha.

Bissexual e usuário de cocaina endovenosa.

Estava ictérico, caquético, afebril. Apresentava AIDS, estafilococcia, candidiase oral, tuberculose, hepatite a esclarecer e desidratação. Apresentava quadro diarréico intenso, dispnéia, cefalcia postural, dores ósseas intensas e estava quase que totalmente dependente da Enfermagem.

PACIENTE $\mathrm{P}_{2}: 24$ anos, sexo masculino, cor branca, solteiro, nivel de escolaridade fundamental, profissão: lavrador. Usuário de maconha.

Apresentava como Impressões Diagnósticas: AIDS, hepatoesplenomegalia, pneumonia, escabiose, adenomegalia, candidiase oral, varicela disseminando e tuberculose. Apresentava-se apático, deprimido com fraqueza e lipotimia intensa, extremamente queixoso pela dor nas lesões vesiculares, irritado e estava dependente da Enfermagem.

PACIENTE $\mathrm{P}_{3}$ : 35 anos, sexo masculino, cor branca, solteiro, nível de escolaridade superior, profissão: escriturário. Bissexual. Apresentava como Impressão Diagnóstica: AIDS, diarréia crônica, lues tratada, icterícia e hepatomegalia a esclarecer. Estava calmo, independente e bastante comunicativo.

Dos 17 elementos da equipe de enfermagem, 13 eram do sexo feminino e quatro masculino; com idade variando de 24 a 52 anos e tempo de serviço na instituição em estudo entre 1 e 27 anos, onde todos com exceção de um trabalham na unidade de Moléstias Infecto-Contagiosas desde a admissão.

Quanto às unidades de interação verbal, foram identificadas 3.492, correspondentes a 156 periodos de observação e 3.336 comportamentos verbais ocorridos entre pacientes aidéticos e a equipe de enfermagem que os assistiam durante o periodo de observação. Destas unidades, 39,46\% (1.378) foram emitidas pelos pacientes e 60,54\% (2.114) pela equipe de enfermagem.

Das categorias emitidas pelos pacientes, as predominantes em ordem decrescente foram: Resposta Especifica (RE) que aloca-se na área $H$ (Aproximação do Tema) da matriz SAVI, Silêncio (SL) localizada na área G (Aproximação de manutenção pessoal) e Participação Pessoal 
(PP) que se enquadra na área D (Aproximação e/ou Afastamento potencial de manutenção pessoal).

O fato da categoria SL ter sido predominante para o paciente, conduz à evidência de que os periodos de observação foram iniciados e concluídos por algum elemento da equipe de enfermagem, pois SL foi uma categoria atribuída para demarcar o começo e fim de cada período de observação. Este fato vem de encontro ao que normalmente é esperado, ou seja, que a equipe de enfermagem dirija sua fala ao paciente tão logo entre na enfermaria, evitando, desta forma, desconsiderar o paciente ou simplesmente fazer algo por ele ou com ele de forma robotizada, sem participá-lo.

Para a equipe de enfermagem foram destacadas as categorias: DE e QT, que são categorias da área E (Aproximação e/ou afastamento potencial do tema); OR, categoria que compõem a área F (Aproximação e/ou afastamento potencial do tema e/ou pessoal) QM que se enquadra na área G (Aproximação de manutenção pessoal). As duas primeiras foram emitidas de forma homogênea pelos atendentes e auxiliares de enfermagem e enfermeiras e a terceira foi identificada pelo atendente e auxiliar de enfermagem e a última foi a mais sobressalente para a enfermeira.

Quanto à distribuição dos 3.336 comportamentos verbais de acordo com o paciente e equipe de enfermagem, ressalta-se que estes dados foram inicialmente lançados em 53 matrizes SAVI, sendo na verdade considerada como uma matriz, o conjunto de 4 matrizes ou quadrantes, respeitando-se o emissor e receptor de cada comportamento verbal. Para efeitos deste estudo, será apresentada apenas uma matriz sintese identificada como Quadro 1.

Este quadro e a Tabela 1 nos revelam que do lançamento dos 3.336 comportamentos verbais, segundo emissor-receptor, obteve-se como matriz mais concentrada de comportamentos, a matriz Eq-Eq, com 1.104 comportamentos verbais, seguida pelas matrizes $\mathrm{P}_{1} \mathrm{P}_{2} \mathrm{P}_{3}$-Eq com 998; Eq$\mathrm{P}_{1} \mathrm{P}_{2} \mathrm{P}_{3}$ com 938 e $\mathrm{P}_{1} \mathrm{P}_{2} \mathrm{P}_{3}-\mathrm{P}_{1} \mathrm{P}_{2} \mathrm{P}_{3}$ que reteve 296 lançamentos.

$\mathrm{O}$ fato do quadrante $\mathrm{Eq}-\mathrm{Eq}$ ter sido o mais freqüente, pode indicar que a equipe emite várias informações sem oferecer tempo para o paciente se manifestar. Esta evidência vem sugerir que este aspecto precisa ser trabalhado a fim de se conseguir transposições de comportamentos verbais deste quadrante para Eq-P e P-Eq, pois estes indicam uma melhor articulação entre o emissor e receptor, principalmente por serem pessoas diferentes.

Para PIERCE (1972), a comunicação "rão é somente a essência ảo ser humano, mas também uma propriedade vital. Os avanços tecnológicos moldam a sociedade e tornam seus membros interdependentes". Relata ainda, que a comuniceção somente acontece entre pessoas com objetivos, metas, curiosidades, interesses comuns e que a comunicação do dia-a-dia é um processo de entendimentos e atitudes ajustáveis, tornando-os congruentes ou averiguando como e onde há concordâncias e discordâncias. 
QUADRO 1

Distribuição dos comportamentos verbais ocorridos entre $P_{1} P_{2} P_{3}$ e a equipe de enfermagem segundo emissor e receptor e áreas de cornportamento verbal do sistema SAVI.

Eq $\mathbf{P}_{1} \mathbf{P}_{2} \mathbf{P}_{3}$

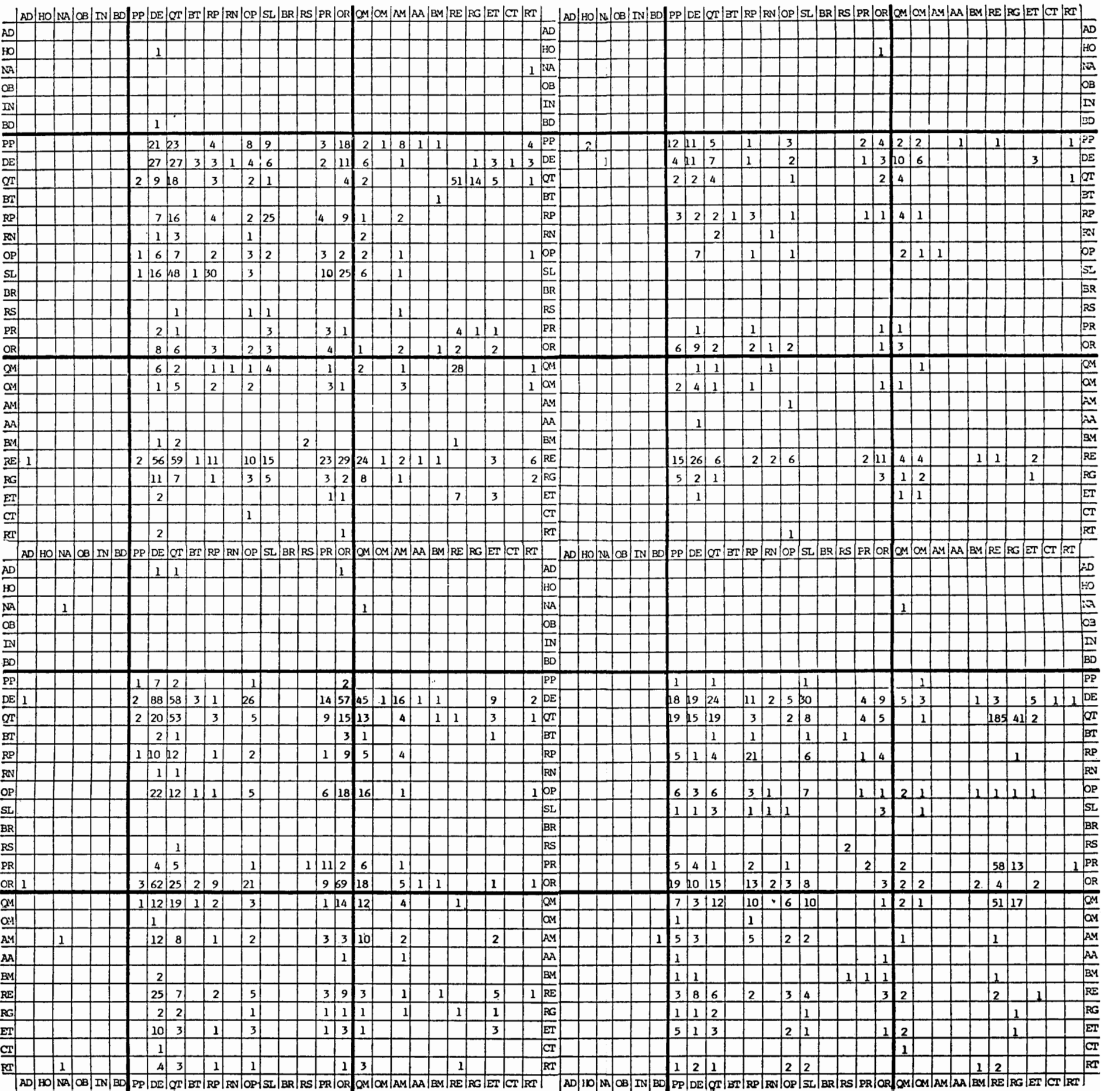


TABELA 1

DISTRIBUIÇÃO DOS COMPORTAMENTOS VERBAIS OCORRIDOS ENTRE PACIENTES $\mathrm{P}_{1} \mathrm{P}_{2} \mathrm{P}_{3}$ E EQUIPE DE ENFERMAGEM, AO LONGO DAS 15 SESSOES, SEGUNDO EMISSOR E RECEPTOR E AREAS DE COMPORTAMENTOS VERBAIS DA MATRIZ SAVI.

\begin{tabular}{|c|c|c|c|c|c|c|c|c|c|c|}
\hline \multirow{3}{*}{$\begin{array}{c}\text { Areas } \\
\text { de } \\
\text { CV }\end{array}$} & \multicolumn{8}{|c|}{ Emissor/Receptor } & \multirow{3}{*}{\multicolumn{2}{|c|}{$\underset{N^{2}}{\text { Total }}$}} \\
\hline & \multicolumn{2}{|c|}{$\mathrm{p}_{1} \mathrm{p}_{2} \mathrm{p}_{3}-\mathrm{Eq}$} & \multicolumn{2}{|c|}{$p_{1} p_{2} p_{3}-p_{1} p_{2} p_{3}$} & \multicolumn{2}{|c|}{$\mathbf{E q}-\mathbf{E q}$} & \multicolumn{2}{|c|}{$\mathrm{Eq}-\mathrm{p}_{1} \mathrm{p}_{2} \mathrm{p}_{3}$} & & \\
\hline & $N^{\circ}$ & $(\%)$ & $\mathrm{Ne}$ & $(\%)$ & $N^{\circ}$ & $(\%)$ & $\mathrm{N}^{\circ}$ & $(\%)$ & & \\
\hline $\mathbf{A}$ & 0 & $(0)$ & 1 & $(0,34)$ & 1 & $(0,09)$ & 0 & $(0)$ & 2 & $(0,06)$ \\
\hline $\mathbf{B}$ & 2 & $(0,20)$ & 1 & $(0,34)$ & 3 & $(0,27)$ & 0 & (0) & 6 & $(0,18)$ \\
\hline $\mathbf{C}$ & 1 & $(0,10)$ & 0 & (0) & 1 & $(0,09)$ & 1 & $0,11)$ & 3 & $(0,09)$ \\
\hline $\mathbf{D}$ & $\mathbf{0}$ & $(0)$ & 3 & $(\mathbf{1}, 01)$ & 2 & $(0,18)$ & 0 & (0) & 5 & $(0,15)$ \\
\hline $\mathbf{E}$ & 480 & $(48,10)$ & 130 & $(43,92)$ & 703 & $(63,68)$ & 375 & $(39,98)$ & 1688 & $(50,60)$ \\
\hline $\mathbf{F}$ & 137 & $(13,73)$ & 44 & $(14,86)$ & 161 & $(14,58)$ & 344 & $(36,67)$ & 686 & $(20,56)$ \\
\hline $\mathbf{G}$ & 1 & $(0,10)$ & 0 & $(0)$ & 2 & $(0,18)$ & 1 & $(0,11)$ & 4 & $(0,12)$ \\
\hline $\mathbf{H}$ & 281 & $(28,15)$ & 97 & $(32,77)$ & 176 & $(15,94)$ & 130 & $(13,86)$ & 684 & $(20,50)$ \\
\hline $\mathbf{J}$ & 96 & $(9,62)$ & 20 & $(6,76)$ & 55 & $(4,98)$ & 87 & $(9,27)$ & 258 & $(7,73)$ \\
\hline Total & 998 & $(100)$ & 296 & $(100)$ & 1104 & $(100)$ & 938 & $(100)$ & 3336 & (100) \\
\hline
\end{tabular}

CLARK (1981), investigando o que as enfermeiras e pacientes cirúrgicos dizem um ao outro observou que os pacientes fazem poucas perguntas diretas, muitas indiretas ou insinuam perguntas ou fazem afirmações, interpretađas como "dicas"; e encontram poucos exemplos de enfermeiras, fazendo perguntas abertas ou de reforço ativo e muito pouca evidência do uso da técnica de reflexão, bem como poucos exemplos de respostas positivas. Por outro lado, em muitos momentos diagnostica que as enfermeiras fazem perguntas fechadas e também omitem ou evitam questões indiretas. Esse autor acrescenta, ser imprescindivel que a enfermeira seja capaz de empregar uma série de habilidades verbais, que incluem a capacidade de fazer perguntas apropriadas, ouvir, explorar um tema, manter um diálogo, reconhecer e responder às perguntas dos pacientes e para Ivey, segundo CLARK (1981); estes são os comportamentos ou técnicas que podem encorajar um diálogo.

Retomando-se à Tabela 1 , observa-se em suas linhas que dos totais gerais de comportamentos verbais, segundo a área, a predominante foi a área $\mathrm{E}$ com $1.688(50,66 \%)$ comportamentos seguida pela $\mathrm{F}$ com 686 $(20,56 \%), \mathrm{H}$ com $684(20,54 \%)$ e J, apresentando 258 (7,73\%). Analisando-se verticalmente, ou seja, as colunas tem-se que as áreas prioritárias em freqüência de acordo com o emissor e receptor foram as matrizes $\mathrm{P}_{1} \mathrm{P}_{2} \mathrm{P}_{3}-\mathrm{Eq}, \mathrm{P}_{1} \mathrm{P}_{2} \mathrm{P}_{3}-\mathrm{P}_{1} \mathrm{P}_{2} \mathrm{P}_{3}, \mathrm{Eq}-\mathrm{Eq}$, destacando-se porém para a matriz 
Eq- $\mathrm{P}_{1} \mathrm{P}_{2} \mathrm{P}_{3}$ a seqüência $\mathrm{E}, \mathrm{F}, \mathrm{H}$. Nas áreas $\mathrm{A}, \mathrm{B}, \mathrm{C}, \mathrm{D}, \mathrm{E}, \mathrm{G}$, praticamente não foram registrados comportamentos verbais.

A seqüência EFHJ foi, portanto, identificada como o padrão de comportamento verbal desta pesquisa, dada a sua predominância na maioria das matrizes estudadas.

Para SIMON \& AGAZARIAN (1967), a área E traduz os comportamentos que conduzem mensagens com potencial de serem usadas pelo grupo. Alguns dos comportamentos que aparecem na área $\mathrm{E}$ são repetidos usos de opinião, descrição, compartilhar informações pessoais sobre sua própria história de vida ou estado mental e propósitos. O uso destas categorias aumenta a informação pessoal de que o grupo dispõe, enquanto que elevada freqüência de comportamento SL-SL ou BR-BR indicam não estar o grupo comunicando-se verbalmente; ainda que esteja em sessão; no primeiro caso nada está sendo dito, no segundo estão sendo comunicadas muitas mensagens que o observador não pode ouvir claramente, para efetuar o registro.

Nesta investigição, a freqüiência de SL-SL esteve presente, embora, não apresente o mesmo significado relatado por SIMON \& AGAZARIAN (1967), uma vez que esta categoria foi empregada neste trabalho, somente para demarcar o início e fim do período de observação. $O$ comportamento BR-BR inexistiu nesta investigação.

$\mathrm{A}$ área $\mathrm{F}$ mostra como o grupo reage às novas informações, sendo trazidas para ele. A área $\mathrm{H}$ indica que os elementos estão se distanciando dos comportamentos de afastamento e prociuzindo, potencialmente, novas fontes de recursos dentro do grupo. Quando há formação de área $F$ ou $\mathrm{J}$ também, indica que o grupo está usanço seus recursos para solução de problema, como ocorreu nesta investigação.

A área J representa os comportamentos de sentimentos, apoiar alguém em nível pessoal, a estruturar, esclarecer ou aceitar icéeias, que contribuam para uma solução de problema de manutenção e tarefa do grupo.

Forte concentração nesta área indica que o grupo está trabalhando para melhorar a sua eficiência interpessoal, aumentado a habilidade de comunicação; oferecendo oportunidade para expressar sentimentos e considerar os feedbacks.

As áreas E e F revelam, portanto, que a comunicação ocorrida entre os pacientes portadores de AIDS e a equipe de enfermagem apresentam comportamentos significativamente claros ou obscuros neles mesmos, isto é, as relações funcionais entre os componentes da informação temática e temática e/ou pessoal são determinados por relativa ambigüidade ou contradição. Estas áreas preenchidas demonstram que o emissor busca informações, introduz senso de humor, expõe sua preferência e sentimentos, permitindo certa abertura a esta interação e é uma situação do qual o paciente, principjolmente, se beneficia ao tê-la. Nas áreas $\mathrm{H}$ e J tem-se por outro lađo, a evidência de comportamentos verbais cujas mensagens são relativamente claras, não ambiguias, nem contraditórias, 
quer seja nas relações funcionais entre os componentes da informação temática e temática e/ou pessoal. Seria ideal se a área J tivesse ocorrido $\mathrm{cm}$ primeiro lugar de freqüência, entretanto neste estudo esta área figura em quarto lugar, segundo predominância seqüencial.

Parece, entretanto, positivo ter atingido este padrão de comportamentos que variam de relativa ambigüidade quanto à clareza das mensagens, até as mensagens limpas e não contraditórias. Destaca-se ainda, outro aspecto favorável, o da inexistência de comportamentos de afastamento, os que apregoam mensagens obscuras e cujas relaçōes funcionais entre os componentes pessoal e temático da informação são ambígüos e contraditórios.

$\mathrm{Na}$ revisão de literatura específica, não foi encontrado nenhum trabalho onde tenha sido utilizado o sistema SAVI; fato este que conduz a iriterpretações limitadas desta pesquisa.

Em conseqüência, releva-se a importância que a diversificação de empregos de instrumentos oferece, tanto em termos de proporcionar alterrativas de escolha para estudos e reprodução de investigações, como no aspecto de permitir que situações semelhantes sejam analisadas e estudadas sob diversos enfoques.

$\mathrm{E}$ reconhecida a inexistência de um sistema de comportamento verbal que trate, especificamente, da situação hospitalar e Enfermagem. A utilização dos instrumentos existentes é pertinente mediante adequação e/ou validação, conforme se pode constatar em CARVALHO (1979) que estudou a interação verbal enfermeiro-paciente, durante o procedimento de punção venosa, valendo-se do paradigma de Skinner. MENDES (1986), pesquisou a interação verbal em situações de enfermagem hospitalar baseando-se no paradigma de Bales; SCOCHI (1986), investigou as informações verbalizadas pelas puérperas no que diz respeito à higiene alimentar do recém-nascido, utilizando-se da análise de conteúdo.

Sobre a variabilidade nas interações verbais ocorrida entre os sujeitos em estudo, construiu-se o Quadro 2 que apresenta os valores de $R$ obtidos em cada uma das nove áreas, identificados por $R_{A}, R_{B}, R_{C}, R_{D}$, $R_{E}, R_{F}, R_{G}, R_{H}, R_{j}$ e tambérn $R_{A} \rightarrow J$ de cada quadrante, ou seja, o cálculo da quantidade de informação total da matriz, segundo emissor e receptor.

Dos dados apresentados, despontam os valores mínimos e máximos obtidos. O valor de $\mathrm{R}=0,0405$ corresponde à área $\mathrm{F}$ da matriz cuja interação se deu entre a equipe de enfermagem e os pacientes $\mathrm{P}_{1}, \mathrm{P}_{2}, \mathrm{P}_{3}$; enquanto em relação aos quadrantes totais destaca-se o $R_{A} \rightarrow J$ da matriz $\mathrm{P}_{1} \mathrm{P}_{2} \mathrm{P}_{3}-\mathrm{P}_{1} \mathrm{P}_{2} \mathrm{P}_{3}$ onde se identifica $\mathrm{R}=0,0336$.

Com respeito aos valores máximos, faz-se ressalva aos valores de $R=0,3065$, que resultou na área $F$, da matriz $\mathrm{P}_{1} \mathrm{P}_{2} \mathrm{P}_{3}-\mathrm{Eq}, \mathrm{R}_{\mathrm{A}} \rightarrow_{j}=$ 0,1382 obtido no quadrante Eq-Eq.

Conforme elucida STEPHANECK (1971), $\mathrm{R}$ tem sempre valor positivo ou nulo, sendo nulo, quando as distribuições de $\mathrm{x}$ e y são independentes, portanto um diálogo estereotipado, onde não há trocas de infor- 


\section{QUADRO 2}

DISTRIBUIÇAO DA QUANTIDADE DE INFORMAÇÃO TRANSMITIDA NA INTERACAAO VERBAL ENTRE OS PACIENTES $\mathbf{P}_{1} \mathbf{P}_{2} \mathbf{P}_{3}$ E A EQUIPE DE ENFERMAGEM, SEGUNDO AS AREAS DA MATRIZ SAVI E EMISSOR E RECEPTOR DE CADA QUADRANTE.

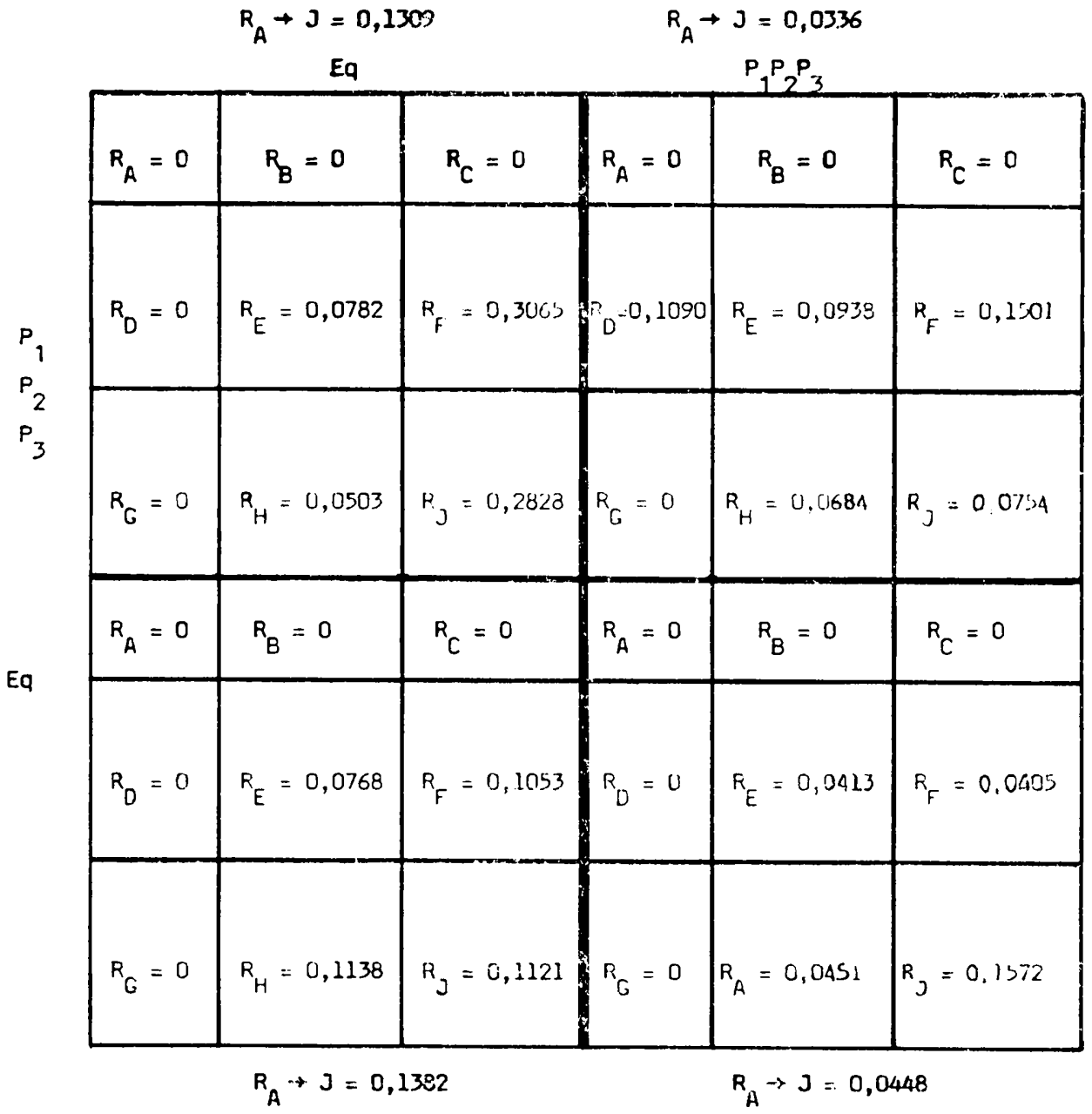

mações. Quanto maior for o valor de $R$, ou seja, quanto mais distantes estiver de zero, maior é a quantidade de informação transmitida entre as pessoas, logicamente, maior será a variabilidade no diálogo e mais rica a interação.

Os resultados levantados obtidos nesta investigação vêm sugerir, portanto, que as interações verbais tidas entre os pacientes $P_{1}, P_{2}$ e $P_{3}$ e a equipe de enfermagem, tendem a se distanciar da estereotipia, ou 
seja, de um diálogo viciaco, onde se obteria padrões de respostas préestabelecidas.

Por outro lado, crê-se ser uma questão que, se trabalhada, pode oferecer diálogos mais ricos, com valores de $\mathrm{R}$ mais elevado.

Pelo levantamento bibliográfico realizado, ficou evidente a inexistência do emprego deste tratamento estatístico na enfermagem ou mesmo em situações hospitalares. FAULKNER (1979) e (STOCKWELL 1972 apud CLARK, 1981), afirmam que os diálogos entre enfermeiros e pacientes tendem a ser superficiais e estereotipados, comentando ainda quão inedequada é esta comunicação. Estes comentários, entretanto, não se embasam na Teoria da Informação.

Este fato gera inquietação na medida em que faz refletir sobre o conhecimento e aplicabilidade dos instrumentos pela área da Enferma. gem. Um outro aspecto que conduz a dificuldades é a impossibilidade de comparar estes dados aos obtidos em outras pesquisas e somar subsídios para interpretar os resultados presentes.

Trata-se de um tratamento de indiscutivel importância, podendo bem contribuir para o cnriquecimento das pesquisas, conseqüentemente para a prática aplicada.

\section{CONSIDERAÇOEES FINAIS}

Do estudo realizado deprcende-se que:

- as categorias do sistema SAVI, predominantemente, emitidas pelo atencente de enfermagem, auxiliar de enfermagem e enfermeiras foram: Descrição (DE) e Questões sobre o tema (QT). Em terceiro lugar, obteve-se a categoria Ordem (OR) para o atendente e auxiliar e Questões de Manutenção (QM) para a enfermeira. Para o paciente, sobressaíram-se as categorias Resposta Especifica (RE), Silêncio (SL) e Participação Pessoal (PP).

- Obteve-se maior freqüência de comportamentos verbais no quadrante Eq-Eq.

- As áreas prioritárias de freqüência de comportamentos verbais, segundo sistema SAVI, foram: E, F, H, J; seqüência esta que identificou o padrão de interação verbal, para os pacientes com diagnóstico de AIDS e equipe de enfermagem.

— Os cálculos de variabilidade mínima obtida nas interações verbais foram:

$$
\begin{aligned}
& \mathrm{R}_{\mathrm{F}}=0,0405 \text { - matriz } \underset{\mathrm{Eq}}{\mathrm{Eq}}-\mathrm{P}_{1} \mathrm{P}_{2} \mathrm{P}_{3} \\
& \mathrm{R}_{\mathrm{A}} \rightarrow \mathrm{j}
\end{aligned}
$$

e os valores máximos corresponderam a:

$$
\begin{aligned}
& \mathrm{R}_{\mathrm{F}}=0,3065 \text { - Matriz } \mathrm{P}_{1} \mathrm{P}_{2} \mathrm{P}_{3}-\mathrm{Eq} \\
& \mathrm{R}_{\mathrm{A}} \rightarrow_{\mathrm{j}}=0,1382 \text { - matriz Eq-Eq }
\end{aligned}
$$


- Há necessidade çe que atenção específica seja dada à comunicação em Enfermagem, quer nos cursos de graduação, quer nos cursos de formação de auxiliar de enfermagem, bem cono em cursos de reciclagem a todos da equipe de enfermagem.

- A inexistência de estudos que empregaram o sistema SAVI e o cálculo da quantidade de informação transmitida dificultaram interpretaçõcs e associações destes dados ao de outras pesquisas; considera-se, todavia importante a introdução deste instrumento à Enfermagem.

GIR, E. \& MORIYA, T.M. Verbal interaction between the nursing team and the AlDS patients. Rev. Esc. Enf. USP, São Paulo, 24(2):301-313, Aug. 1990.

3,336 verbal behaviors between 3 AIDS patients and a nursing team were analized. The pattern and priority areas of verbal behaviors which occur, according to the SAVI system, as well as the amount of information transmitted were determined.

The results showed that the verbal behaviors ranged from relative ambiguity in terms of message clarity to clean and non-contradictory messages. The interaction tended to move away from stereotypy.

UNITERMS: AIDS. Nurse-patient relations.

\section{REFERENCIAS BIBLIOGRAFICAS}

CARVALHO, E.C. Comportamento verbal e enfermagem: a interacão verbal enfermeiro-paciente durante o procedimento de puncão venosa. Ribeirão Preto, 1979. 110p. (Dissertacão de mestrado - Escola de Enfermagem de Ribeirão Preto/USP).

CARVALHO, E.C. Comportamento verbal enfermeiro-paciente: função educativa e educacăo continuada do profisstonal. Ribeirão Preto, 1985. 225p. (Tese de doutorado - Escola de Enfermagem de Ribeirão Preto/USP).

CHRIST, G.H. \& WIFHER, L.S. Psychosocial issues in AIDS. In: DE VITA Jr. et alii. AIDS: etiology, diagnosis, treatment and prevention. Phlladelphia, Lippincott, 198E. p. 275-97.

CLARK, J.M. Communication in nursing. Nurs. Times, London, 77(1):12-8, Jan. 1981.

EDWARDS, E. Introdnção a teoria da informação. Săo Paulo, Cultrix, 1971. 151p.

FAULKNNER, A. Monitoring nurse: patient conversation in a ward. Nurs. Times, London $78(23)$ :95-6, Aug. 1979.

FAVRrGE, J.M. Note sur quelques statistiques empruntées a la théorle de L'information. Bull Centre d'études Bech. Psychotoch., 8(1):2, 1954.

GIR, E. Interaç̆o verbal entre a equipe de enfermagem e pacientes aldéticos. Ribeirăo Preto, 1988. 210p. (Dissertação de mestrado - Escola de Enfermagem de Rtbelrăo Preto/USP).

GILLON, R. Refusal to treat AIDS and HIV positive patients. Br. Mod. J., London, 294: 1332-3, May 1987.

HEWITT, H.E. \& PESZNECKER, B.L. Blocks to communicating with patients. Am. J. Nurm., New York, 64(7):101-3, Jul. 1964.

KELLY, J.A.; LAWREANCE, J.S.St.; SMITH Jr., S.; HOOD, H.V.; COOK, D.J. Stigmatization of AIDS patients by physicians. Am. J. Public. Health., Washington, 7r(7):789-91, Jul. 1987. 
LACAZ, C. da S. AIDS: dontrina, aspectos iatrofilosfficos, infeccóas oportunistas aseociadas. Săo Paulo, Sarvier, 1985. 124p.

MACIEL, P.M.A. Os enfermeiros frente ao paciente com sindrome de imunodeficiencia adquirida (SIDA/AIDS): uma proposta de assistência de enfermagem. Rlo de Janeiro, 1987. 151p. (Dissertacăo de mestrado - Escola de Enfermagem Ana Néri/UFRJ).

MENDES, I.A.C. Interação verbal em situações de Enfermagem Hospitalar: enfoque humanistico. Ribeirăo Preto, 1986. 175p. (Tese de doutorado - Escola de Enfermagem de Ribeiræ̃o Preto/USP).

MEZOMO, J.C. Hompital hnmanizado. CESC. Centro de Desenvolvimento em Administraçăo de Saude. S\&̊o Paulo, 1979.

NICHOLS, S.E. Psychiatric aspects of AIDS. Psychooomatios, Greenwich, 24(12):1083-9, Dec. 1883.

OLIVEIRA, M.H.P.; VIETTA, E.P.; MORIYA, T.M.; GIR, E. Reač̃es emocionals dos portadores de doenças sexualmente transmissiveis no momento da confirmaç̆o do seu diagnóstico. Hev. Bras. Enf., Brasilia, 40(1):38-42, jan./mar. 1987.

PIERCE, J.R. Communication. Sci. Am., New York, 227(3):31-41, Sept. 1972.

ROSNER, F.: SHAPIRO, S.: BERNABO, L.: HOWARD, F. Psychosocial care team for patients with AIDS in a municipal hospital. JAMA, Chicago, 253(16):2361, Apr. 1985.

SCOCHI, C.G.S. Higlene alimentar do recém-nascido: estudo das informacões verbalizadas pelas puérperas. Rlbeirăo Preto, 1986. 199p. (Dissertaçăo de mestrado - Fscola de Enfermagem de Ribeirko Preto/USP).

SIMON, A. \& AGAZARIAN, Y. Sequential analysis of verbal intaraction. Philadelphia, Research for Better Schools, 1967. $109 \mathrm{p}$.

STEPHANECK, P. Efeito da incerteza no tratamento da informacăo pelo sujelto humano. Arq. Bras. Palo. Aplio., Rlo de Janeiro, 23(1):27-38, jan./mar. 1971.

STOCKWHLL, F. apud CLARK, J.M. Communication in nursing. Nurs. Times, London, $77(1): 12-8$, Jan. 1981.

Recebido em 02-10-89. 